\title{
Effect of Pouring 'Temperature on Microstructure and Properties of A356 Alloy Strip by a Novel Semisolid Micro Fused-Casting for Metal
}

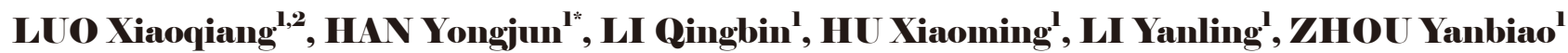 \\ (1. Henan Key Laboratory of Research for Central Plains Ancient Ceramics, Pingdingshan University, Pingdingshan 467000, China;2.Insti- \\ tute of Mechanics, Chinese Academy of Sciences, Beijing 100190, China)
}

\begin{abstract}
A novel semisolid micro fused-casting (MFC) for preparing A356 alloy strips is proposed, and the effects of process parameters of pouring temperature on the microstructure and properties of A356 alloy strips are investigated. MFC means that the semisolid metal slurry was pressed out from the outlet of bottom of crucible to the movable plate, and directly solidified and formed layer by layer. The microstructure and properties of A356 semisolid alloy slurry were influenced by the cooling conditions. Results show that the aluminu alloy A356 strip samples fabricated by micro fused-casting had good performances and uniform structures with the pouring temperature at $595{ }^{\circ} \mathrm{C}$ and the substrate movement speed at $18 \mathrm{~mm} / \mathrm{s}$. The fine grains of the primary $\alpha$-Al phase with average grain size of $53 \mu \mathrm{m}$ and shape factor up to 0.72 was obtained, the ultimate tensile strength of the aluminum alloy A356 strip reaches $243.79 \pm 3.91 \mathrm{MPa}$, while the average vickers hardness is $82.65 \pm 1.86 \mathrm{HV}$.
\end{abstract}

Key words: A356 alloy; semisolid; micro fused-casting; pouring temperature

\section{Introduction}

Aluminium-silicon alloys are widely used in the field of aviation, aerospace and automobile industry not only because they are easily castable in complex forms but also because of their excellent wear resistance $\mathrm{e}^{[1-4]}$. Aluminium alloy A356 is one of the most popular aluminium silicon alloys which is used in the casting processes because of their excellent castability, heat treatability and mechanical properties ${ }^{[5-7]}$. As one of the lightest structural materials, A356 alloy has widespread applications for structural components in the automobile for reducing the mass of transportation, and reducing the fuel consumption and air pollution ${ }^{[8,9]}$. Semisolid metal slurry forming technology generally attracted the attentions of scholar due to a lot of merits, such as near net shape, saving energy, and low forming force ${ }^{[10,11]}$. In particular, semisolid forming is an ideal way to fabricate aluminium alloy products because of good flowability ${ }^{[12-15]}$.

(C) Wuhan University of Technology and Springer-Verlag GmbH Germany, Part of Springer Nature 2019

(Received: Apr. 18, 2018; Accepted: June 17, 2019)

LUO Xiaoqiang(罗晓强): Ph D; Assoc. Prof.; E-mail: 1xq.5566 @ $163 . c o m$

*Corresponding author:HAN Yongjun(韩永军): Ph D; Prof.; E-mail:hyj73@126.com
As a new kind of without mold molding method, micro fused-casting (MFC) for metal is a technology in the field of additive manufacturing technology, which usually need a semisolid metal slurry as raw materi$\mathrm{al}^{[16,17]}$. The machine of the process mainly includes a crucible, a stirring apparatus, and a horizontal movable plate. During the process, a liquid alloy is poured into the crucible under proper temperature and stirring, and the liquid alloy transforms into the semisolid slurry. The semisolid slurry in the gap is forced to flow along the movement direction, then the cooling is caused by the movement of horizontal movable plate, and the semisolid slurry is transformed into a strip materials. The process has two advantages. First, the microstructure of the alloy strip produced by the process is mainly composed of fine non-dendrites, and the mechanical properties of the product are better than that of a strip produced by conventional process. Second, the energy consumption is much less than that of the normal casting because the temperature of semisolid slurry is much lower than that of liquid alloys.

In this paper, the A356 alloy strip was prepared by MFC, which is as a novel technique with high performance, short course and net-shape. In the process, effects of the pouring temperature by MFC on the microstructure and mechanical property of A356 alloy has been studied. The results show that the A356 alloy strip 
sample fabricated by MFC display a good performance and uniform structure with pouring temperature of 595 ${ }^{\circ} \mathrm{C}$ and the velocity of the substrate is controlled to about $18 \mathrm{~mm} / \mathrm{s}$.

\section{Experimental}

\section{I Material}

The experimental material was a commodity A356 aluminum alloy whose main chemical compositions (mass fraction,\%) were Si 7.21,Fe $0.28, \mathrm{Mg}$ $0.23, \mathrm{Zn} 0.22$ and $\mathrm{Al}$ balanced.

\subsection{Principle of micro fused-casting for metal}

The schematic diagram of MFC process apparatus is shown in Fig.1. It consists of a heating furnace, heating system with a crucible heating and a movable plate. During the process of such technique, the uniform semisolid slurry is prepared in crucible and pressured through a nozzle to a micro fused area, $i e$, an open flat space between the plate and the nozzle with diameter and thickness both in millimeters. Meanwhile, the plate, served as cooler and crystallizer, moves horizontally in a withdrawn out of the micro fused area. By means of 3D controlling system, liquid slurry is filled and solidified in given patterns layer by layer, and then a metal part is formed. Between the mouth and crystallization plate cavity area, the metallic melts begin to solidification rapidly, and the dendrite rapidly formed by metallic melts. The A356 aluminum alloy strip was prepared by this process, and the pouring temperature take great effect on the morphology of the primary $\alpha$-Al phase and the mechanical properties of A356 aluminum alloy strip.

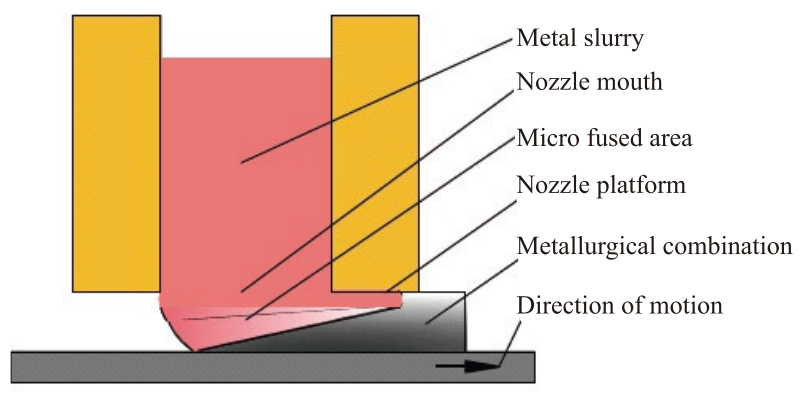

Fig.1 MFC equipment

\subsection{Alloy preparation}

In order to obtain fine and globular microstructure, the A356 aluminum alloy were heated to a temperature between liquids and solidus zone which is sufficient condition required for the forming. In this experiment, we choose the pouring temperature at dif- ferent temperature, the velocity of the substrate is 18 $\mathrm{mm} / \mathrm{s}$, and the pouring temperature is higher than that of the nozzle. The samples for microstructure observation were prepared by standard metallographic techniques. For microstructures observation samples were cut off from the quenched slurries, roughly ground, polished and etched by an aqueous solution of $0.5 \%$ $\mathrm{HF}$ for $15 \mathrm{~s}$, then analyzed by optical microscopy (OM), and the representative microstructure of the slurry can be obtained. All the metallographic samples were examined by OM, scanning electron microscopy (SEM) and energy dispersive spectrometer (EDS). T1 thermal treatment of the samples involved artificial aging. Therefore, this window of heated temperature could be controlled within liquids temperatures and solidus temperatures to get a proper solid fraction and degree of superheat

\section{4 'Testing methods}

The average roundness of the grain shape was calculated by

$$
S=\frac{L_{\mathrm{p}}^{2}}{4 \pi A_{\mathrm{p}}}
$$

The average roundness of the grain shape was calculated by image analysis software. $S$ is the average roundness, $A_{\mathrm{P}}$ and $L_{\mathrm{P}}$ are grain areas value of globule and total circumference of measure grains, respectively.

The average grain size was calculated by

$$
D=\frac{L_{\mathrm{f}}}{N_{\mathrm{f}} \times \mu}
$$

The $D$ is the average grain size, $N_{\mathrm{f}}$ is the grain count, $\mu$ is the magnification value and $L_{\mathrm{f}}$ is the length of measure line that is covered by the measure line.

The A356 alloy strip with a cross section size of $8 \times 100 \mathrm{~mm}$ was produced by the proposed process. It has been used for fabricating tensile samples. The tensile samples for mechanical property tests were obtained from middle region, and the tensile test was carried out by a CMT5105 tensile machine. The hardness was test by a XHB-3000 Brilled duromete. The results reported in this work were the average values obtained from the test specimens.

\section{Results and discussion}

\subsection{Differential scanning thermal analysis}

The commodity A356 aluminum alloy were heated to $700 \mathrm{C}$ at $10{ }^{\circ} \mathrm{C} / \mathrm{min}$ and cooled to room temperature. The heat flow and temperature were tested 
with a K-type thermocouple to obtain DSC curves. The liquidus and solidus temperatures of this alloy were 626.33 and $559.21{ }^{\circ} \mathrm{C}$, respectively.

Fig. 2 shows the scanning electron microscopy (SEM) and EDS spectra image of two regions on the commercial A356 aluminum alloy samples which exhibits typical dendritic microstructure. As can be seen from the SEM image, the grey precipitates is $\alpha$-Al (point $\mathrm{b}$ ), the white needle-shaped precipitates is $\mathrm{Si}$ (point c), the shine precipitates is $\mathrm{AlSi}_{9} \mathrm{Mg}$, and the microstructure of A356 alloy is mainly composed of eutectic Si and matrix $\alpha$-Al phase. According to the EDS results of A356 aluminum alloy, it is confirmed that arrow "c" (white needle-shaped precipitates) and the arrow "b" (grey precipitates) in Fig.2 are eutectic Si and eutectic $\alpha$-Al phases, respectively. It is found from Fig.2 that the A356 aluminum alloy has microstructure in complex irregular shape, the $\alpha-\mathrm{Al}$ is grey precipitates alloy exhibiting a large block shape, and the Si phase is needle-shaped.

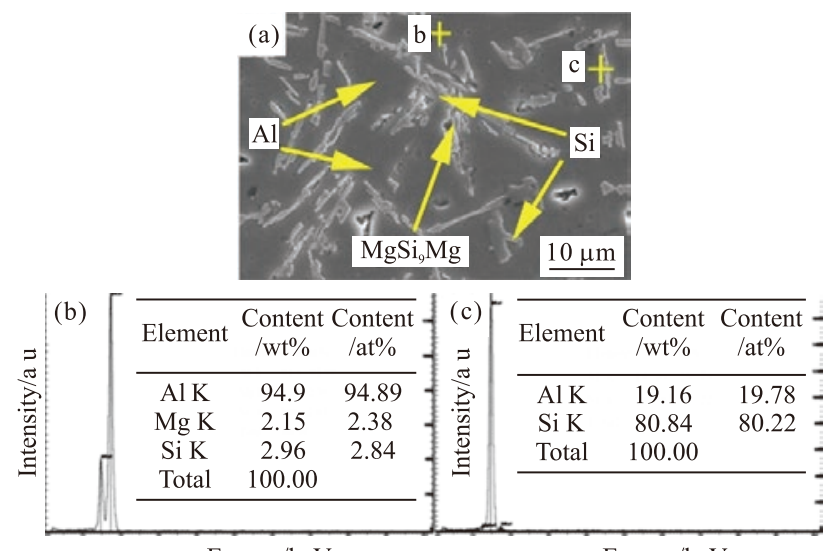

Energy/keV

Energy/keV

Fig.2 (a) SEM image of A356 alloy samples and energy spectrum of (b) point b in (a); (c) point $\mathrm{c}$ in (a)

\subsection{Microstructure of the $\mathbf{A 3 5 6}$ semisolid alloy}

During the MFC process, in preparation of semisolid metallic melts for micro fused-casting using the temperature control and mixing system, the dendrite become round and short grain under the action of shear force in the areas of fused-casting. Fig. 3 shows the optical microstructure (OM) images of A356 alloys prepared by MFC with different pouring temperature which were $590{ }^{\circ} \mathrm{C}$ (Fig.3(a)), $595{ }^{\circ} \mathrm{C}$ (Fig.3(b)), $600{ }^{\circ} \mathrm{C}$ (Fig.3(c)) and $605{ }^{\circ} \mathrm{C}$ (Fig.3(d)), respectively. Four samples are cooled at room temperature (T1 state). The process of MFC is focused on melting and solidification. So, a proper pouring temperature was the key factor to achieve short and fine grains. The pouring temperature at $595{ }^{\circ} \mathrm{C}$ has a uniform microstructure and there is the fewest dendritic.
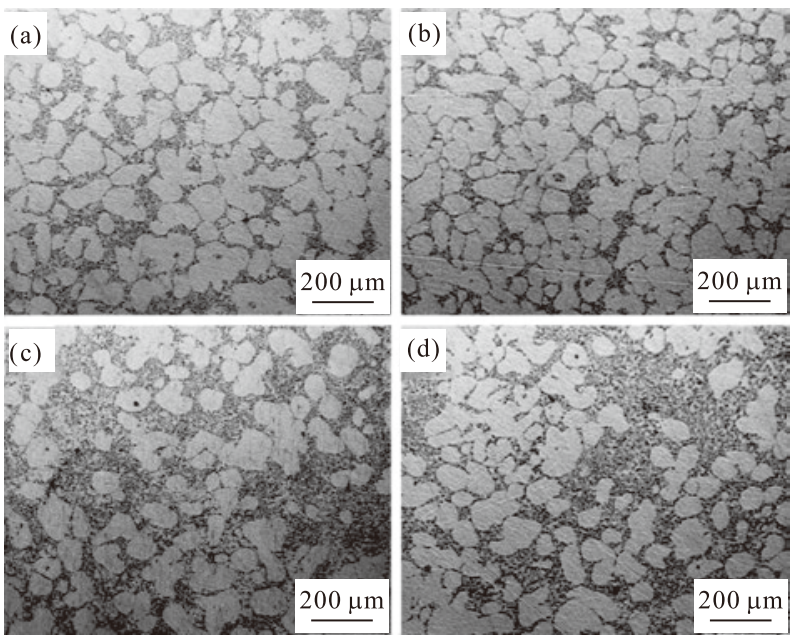

Fig.3 OM images of the A356 alloy at different pouring temperature: (a) $590{ }^{\circ} \mathrm{C}$, (b) $595{ }^{\circ} \mathrm{C}$, (c) $600{ }^{\circ} \mathrm{C}$, (d) $605{ }^{\circ} \mathrm{C}$
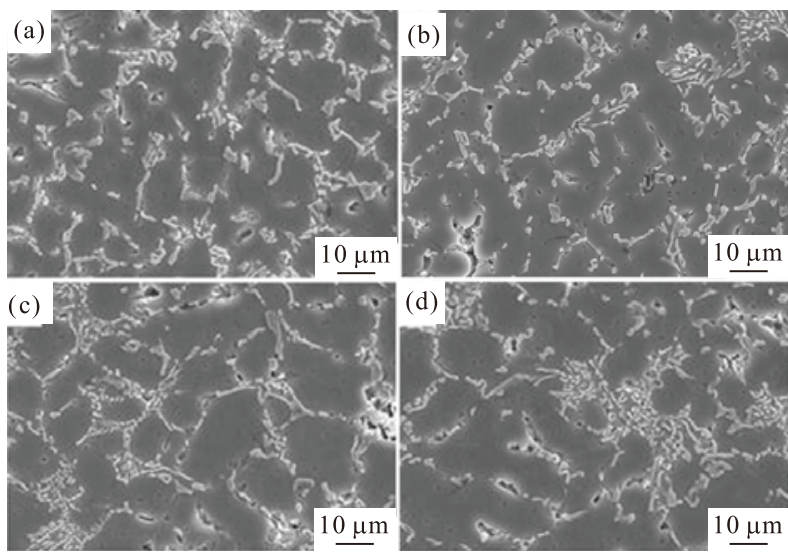

Fig.4 SEM images of the A356 experimental alloy at different pouring temperatures: (a) $590{ }^{\circ} \mathrm{C}$, (b) $595{ }^{\circ} \mathrm{C}$, (c) $600{ }^{\circ} \mathrm{C}$, (d) $605^{\circ} \mathrm{C}$

Fig. 4 shows the scanning electron microscopy (SEM) images of A356 alloys prepared by micro fused-casting with different pouring temperature which were $590,595,600$, and $605{ }^{\circ} \mathrm{C}$, respectively. The samples are molded at high temperature without cold working besides cooling ( $\mathrm{T} 1$ state). It was proved that dendrite nucleation and breakage were the main reasons of fine spherical microstructure formation, and pouring temperature combination with shearing strength can affect the dendrite fusing of the melt. The fused casting velocity affects grain shape, but its impact on grain size is not obvious, and the experimental with the pouring temperature at $595{ }^{\circ} \mathrm{C}$ has a uniform microstructure with very few dendritic. Obviously, SEM images in Fig.4(a) and 4(d) for the pouring temperature at 590 and $605{ }^{\circ} \mathrm{C}$ has segregation, respectively.

3.3 Microstructure and properties of the A356 alloy 




Fig.5 The average grain size and shape factor at different pouring temperatures

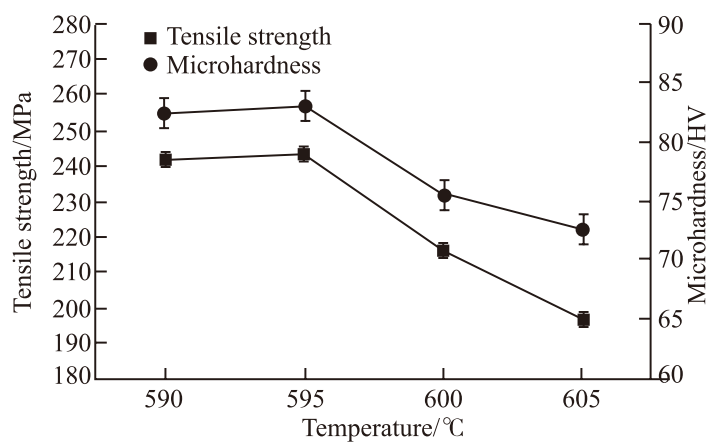

Fig.6 Tensile strength and Vickers hardness of A356 alloy strip at different pouring temperatures

Fig. 5 shows the relationships between the fused casting temperature, average roundness and average grain size. The primary grain size is best developed at pouring temperature of $595{ }^{\circ} \mathrm{C}$, and the pouring temperature can affect the shearing strength and nucleation rate of the melt in the fused casting zones, and further influence the final grain size of the A356 alloy. The roundness and grain size increased with the temperature increasing and decreasing from $595{ }^{\circ} \mathrm{C}$. Furthermore, the liquid fraction of the A356 slurry increased with the increasing increments of the casting temperature, and viscosity decreased correspondingly. As stated, the shearing force in the melt is determined by the pouring temperature and viscosity, so the shearing strength reduces with the decrease of the viscosity of A356 slurry. For this reason, a high fused casting temperature could have caused a weak shearing strength and low nucleation rate, which caused coarse dendrite formation. When the fused casting temperature was between 600 and $605{ }^{\circ} \mathrm{C}$, many obvious big dendrites formed in the microstructures of the A356 semisolid slurry, as shown in Fig.4(c) and 4(d). On the other side, the shearing strength increased, and the roundness and grain size decreased respectively, as shown in Fig.4(a) and Fig.4(b). Nevertheless, if the fused casting temperature was lower than $590{ }^{\circ} \mathrm{C}$, the melt flow ability of the A356 slurry was very poor, and the operation procedure usually failed. At a pouring temperature of $595{ }^{\circ} \mathrm{C}$, the fine grains with average grain size of $53 \mu \mathrm{m}$ and shape factor up to 0.72 was obtained.

Between the mouth and crystallization plate cavity area of MFC, the metallic melts begin to solidification rapidly, and the pouring temperature take great effect on the slurry of metals in the process. At different pouring temperature which were 590,595, 600, and $605{ }^{\circ} \mathrm{C}$, four kinds of A356 alloy strips were produced by fused-casting process. The surface of metal strips were good. The tensile strength samples analysis was conducted on five samples prepared under the same conditions, and the results were averaged of five samples. The vickers hardness is made in the same place of the samples, and the results were averaged of five position in per sample. The tensile strength and vickers hardness of A356 metal strips are shown in Fig.6. The ultimate tensile strength of the aluminum alloy strip reached $243.79 \pm 3.91 \mathrm{MPa}$, while the average vickers hardness is $82.65 \pm 1.86 \mathrm{HV}$, respectively. Obviously, the pouring temperature at $595{ }^{\circ} \mathrm{C}$ could maintain the balance of melting and solidification of the material. For these reasons, we suggest a reasonable fused casting temperature to be $595{ }^{\circ} \mathrm{C}$.

\section{Conclusions}

a) The A356 alloy strip was produced by semisolid continuous micro fused-casting, through which the primary dendritic crystal is easily crushed under proper temperature.

b) The proper pouring temperature could contribute to grain refinement and evenly affect the microstructure and properties of samples. When the pouring temperature of micro fused casting is controlled at 595 ${ }^{\circ} \mathrm{C}$ and the velocity of plate at $18 \mathrm{~mm} / \mathrm{s}$, the optimum microstructure and properties were obtained, the tensile strength and vickers hardness of the samples reached $243.79 \pm 3.91 \mathrm{MPa}$ and $82.65 \pm 1.86 \mathrm{HV}$, respectively.

\section{References}

[1] Sercombe T B, Schaffer G B. Rapid Manufacturing of Aluminum Components[J]. Science, 2003, 301(5 637): $1225-1227$

[2] Liu Z, Mao W, Zhao Z. Effect of Pouring Temperature on Semi-solid Slurry of A356 Al Alloy Prepared by Weak Electromagnetic Stirring[J]. Transactions of Nonferrous Metals Society of China, 2006, 16(1): 71-76

[3] Mazzolani F M. 3D Aluminium Structures[J]. Thin-Walled Structures, 2012, 61: 258-266

[4] Liu Z, Mao W, Zhao Z. Research on Semi-solid Slurry of a Hypoeutec- 
tic Al-Si Alloy Prepared by Low Superheat Pouring and Weak Electromagnetic Stirring[J]. Rare Metals, 2006, 25(2): 177-183

[5] Mao W, Bai Y, Lin H. Effect of Pouring Height on the Solidified Microstructure of AlSi7Mg Alloy[J]. Journal of University of Science and Technology Beijing, Mineral, Metallurgy, Material, 2006, 13(4): 324328

[6] Luo X, Han Y, Li Q, et al. Microstructure and Properties of ZL101 Alloy Affected by Substrate Movement Speed of a Novel Semisolid Continuous Micro Fused-Casting for Metal Process[J]. Journal of Wuhan University of Technology, 2018(03): 715-719

[7] Mao W, Li Y, Zhao A, et al. The Formation Mechanism of Non-dendritic Primary $\alpha$-Al Phase in Semi-solid A1Si7Mg Alloy[J]. Science and Technology of Advanced Materials, 2001, 2(1): 97-99

[8] Zhang H, Wang G, Luo Y, et al. Rapid Hard Tooling by Plasma Spraying for Injection Molding and Sheet Metal Forming[J]. Thin Solid Films, 2001, 390(1): 7-12

[9] Guan R, Zhao Z, Lian C, et al. Microstructure Formation Mechanism and Properties of a Mg-3Sn-1Mn (wt\%) Magnesium Alloy Processed by a Novel Semisolid Continuous Shearing and Rolling Process[J]. Metals and Materials International, 2013, 19(1): 33-38

[10] M Orme. A Novel Technique of Rapid Solidification Net-Form Materials Synthesis[J]. Journal of Materials Engineering and Performance, 1993, 2 (3): 399-407
[11] Qi M, Kang Y, Zhou B, et al. A Forced Convection Stirring Process for Rheo-HPDC Aluminum and Magnesium Alloys[J]. Journal of Materials Processing Technology, 2016, 234: 353-367

[12] Guan R, Zhao Z, Lian C, et al. Mathematic Model of Rolling Pressure During a Semisolid Shearing-rolling Process[J]. International Journal of Minerals, Metallurgy and Materials, 2012, 19(12): 1 121-1 127

[13] Zhang H, Kong F,Wang G, et al. Numerical Simulation of Multiphase Transient Field During Plasma Deposition Manufacturing[J]. Journal of Applied Physics, 2006, 100(12): 123522

[14] Wang X, Yan Y, Pan Y, et al. Generation of Three-dimensional Hepatocyte/gelatin Structures with Rapid Prototyping System[J]. Tissue Engineering, 2006, 12(1): 83-90

[15] Flemings M. Behavior of Metal Alloys in the Semisolid State[J]. Metallurgical Transactions B, 1991, 22(3): 269-293

[16] Luo X, Li Z, Si X, et al. Effect of Stirring Velocity in Micro Fused-Casting for Metal on Microstructure and Mechanical Properties of A356 Aluminum Alloy Slurry[J]. Journal of Wuhan University of Technology, 2016(05): 1 131-1 136

[17] Luo X, Yan Q, Li Z. Effect of the Pouring Temperature by Novel Synchronous Rolling-casting for Metal on Microstructure and Properties of ZL104 Alloy[J]. Journal of Materials Research, 2016, 31(16): 2 5242530 